\title{
Aspectos ecológicos e bionômicos das saúvas da região oriental do Estado de São Paulc ${ }^{1}$
}

FRANCISCO A. M. MARICONI2

Escola Superior de Agricultura "Luiz de Queiroz"

1 - Trabalho realizado com auxílio da Fundação de Amparo à Pésquisa do Estado de São Paulo, apresentado no II Encontro de Técnicos em Agricultura, realizado em Campinas em agôsto de 1965, recebido para publicação em 31-12-1965; 2 - Cadeira de Zoologia da E.S.A. "Luiz de Queiroz". 


\section{RESUMO}

Neste trabalho, são descritos aspectos ecológicos, distribuição por município, importância econômica, etc., das saúvas encontradas na Região Oriental do Estado de São Paulo. Esta região, cuja conformação se assemelha a um "bico", está dividida em 52 municípios.

Três espécies de saúva foram encontradas: 1. ${ }^{\mathrm{a}}$ ) "saúva limão" ou "saúva comum" Atta sexdens rubropilosa Forel, $1908 ; 2 .{ }^{2}$ ) "saúva mata pasto" A . bisphaerica Forel, 1908; 3.) "saúva de vidro" ou "saúva cabeça de vidro" A. laevigata (F. Smith, 1858).

\section{1 - INTRODUÇÃO}

O presente estudo das saúvas da Região Oriental do Estado de São Paulo foi iniciado em junho de 1964 e terminado em dezembro de 1965. Conforme se poderá verificar no capítulo seguinte, até que se completasse êste trabalho, diversas viagens foram realizadas naquela região.

A citada área, compreendendo 52 municípios, por nós arbitràriamente separada do Estado, como se poderá ver na figura $n .^{0} 1$ e seguintes, inicia-se pouco além do município

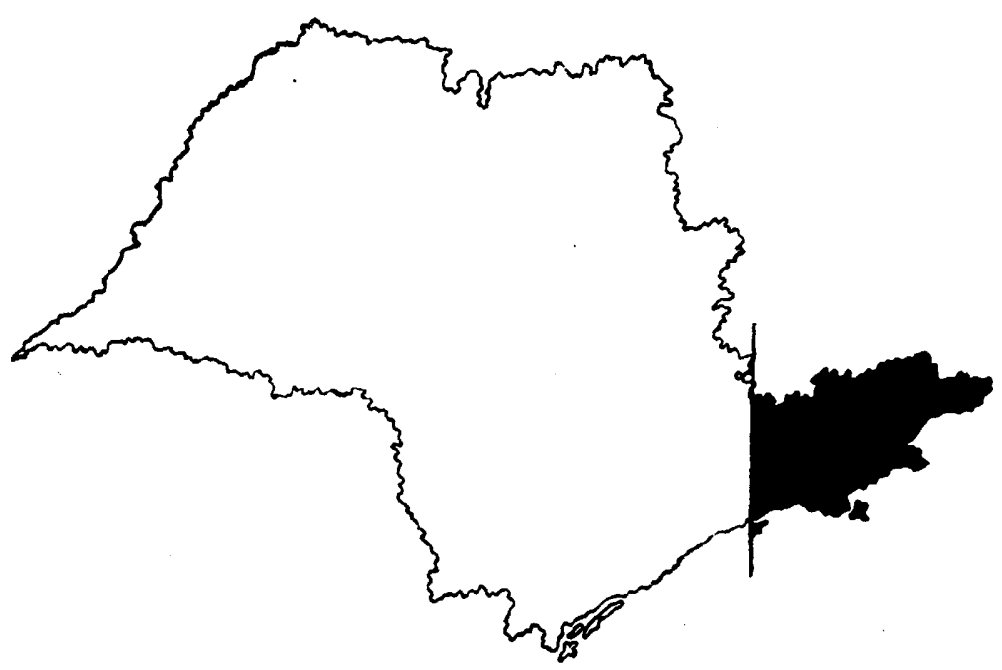

Fig. 1 - Estado de São Paulo. Em negro, Região Oriental do Estado, onde foram realizadas as observações e coletas de material para êste trabalho. 
da Capital do Estado (mais precisamente depois de Guarulhos. A Pegião Oriental é o "bico" ou extremidade que avança sob o sul de Minas Gerais,em direção ao oeste do Estado do Rio de Janeiro.

A região é muito heterogênea, sob qualquer ponto de vista. Com relação à topografia distinguimos: Vale do Paraíba, região da Serra da Mantiqueira, municípios cortados pela Serra do Mar, áreas costeiras, e finalmente, a região próxima à Capital. Com relação à agricultura, o progresso é muito mais nítido no Vale do Paraíba em geral, e na região próxima à Capital; no litoral, pràticamente não há agricultura e, em grande parte das áreas cortadas pelas duas Serras, há quase sòmente pastagens, em que se desenvolve uma Pecuária mais ou menos desenvolvida, embora as pastagens pouco ou nada recebam da atenção dos pecuaristas.

A relação geral dos municípios da região é a seguinte: Aparecida, Areias, Arujá, Bananal, Biritiba Mirim, Brás Cubas, Caçapava, Cachoeira Paulista, Campos do Jordão, Caraguatatuba, Cruzeiro, Cunha, Ferraz de Vasconcelos, Guararema, Guaratinguetá, Guarujá, Igaratá, Ilhabela, Itaquaquecetuba, Jacareí, Jambeiro, Joanópolis, Lagoinha, Lavrinhas, Lorena, Mogi das Cruzes, Monteiro Lobato, Natividade da Serra, Nazaré Paulista, Paraibuna, Pindamonhangaba, Piquete, PiraPoá, Queluz, Redenção da Serra, Roseira, Salesópolis, Santa Branca, Santa Isabel, Santo Antônio do Pinhal, Santos, São Bento do Sapucaí, São José do Barreiro, São José dos Campos, São Luís do Paraitinga, São Sebastião, Silveiras, Susano, Taubaté, Tremembé e Ubatuba. Os municípios de Biritiba Mirim e de Brás Cubas foram criados sòmente em 1965.

\section{2 - REVISÃO DA LITERATURA}

Nada há, pràticamente, sôbre as saúvas da região. As raras citações limitam-se, quase exclusivamente, a lacônicas informaçōes: AMANTE (1960) descreve alguns aspectos bionômicos da $A$. sexdens rubropilosa, de observações realizadas em Biritiba Mirim; ainda com relação a essa saúva, MARICONI \& COL. (1963) citam-na em Salesópolis. Com relação à A. bisphaerica, BORGMEIER (1939) cita-a como presente em Guaratinguetá, GONÇALVES (1960) acrescenta Lorena e ZAMITH \& COL. (1961), Mogi das Cruzes e São José dos Campos. LUEDERWALDT (1926) menciona a $A$. laevigata em Santos. 


\section{3 - MATERIAIS E METODOS}

Este trabalho resultou das seguintes viagens realizadas à Região Oriental: 1. ${ }^{\mathrm{a}}$ ) 18.VI.1964 a 27.VI.1964; 2. ${ }^{\mathrm{a}}$ ) 23.II.1965 a 25.II.1965; 3. ${ }^{a}$ ) 14.III.1965 a 16. III.1965; 4. ${ }^{a}$ ) 23.IV.1965 a 26.IV.1965; 5.a) 29.VII.1965 a 2.VIII.1965 e 6.a) 4.XII.1965 a 8.XII.1965.

$\mathrm{Na}$ primeira, terceira e quarta viagens foram visitados municípios sòmente da região oriental; na segunda, foram também percorridos municípios próximos da Capital, porém localizados fora da região que estamos tratando; na quinta e sexta, os principais objetivos de estudo estavam quase todos situados bem longe. Alguns municípios foram percorridos em ocasiões diferentes, como se poderá ver no capítulo seguinte, que se refere às amostras coletadas.

As viagens foram realizadas em "perua Volkswagen", doada a esta Cadeira pela "FUNDAÇÃO DE AMPARO A PESQUISA DO ESTADO DE SÃO PAULO", a quem agradecemos penhoradamente por êsse e outros valiosíssimos auxílios.

Ao chegarmos a um município, percorríamos uma, duas, três ou mais de suas estradas, à procura de sauveiros. Após a localização dos formigueiros, coletávamos material (operárias), que era introduzido em frasco numerado. com álcool a $70 \%$. A seguir, tomavam-se notas de tudo que fôsse interessante: dimensões dos grandes sauveiros, características dos carreiros, plantas cortadas, etc.

Após a coleta de uma espécie de saúva, continuava a procura de outras espécies. Às vêzes, por motivo especial, duas amostras da mesma espécie foram coletadas num município. Depois de coletadas as várias espécies, passava-se a outro município; o procedimento era idêntico, quando era impossível a localização de mais de uma ou de duas espécies.

No laboratório, as amostras foram identificadas, visto que a identificação preliminar, realizada no campo, podia conduzir a êrro. Após a identificação definitiva, as formigas eram lavadas e passadas para outro tubo, também rotulado, com álcool limpo a 70\%. Tôdas as amostras estão no laboratório da Cadeira de Zoologia, desta Escola.

\section{4 - MATERIAL COLETADO}

A) Atta sexdens rubropilosa Forel, 1908

Conhecida em São Paulo, Espírito Santo, sul de Minas 
Gerais, Rio de Janeiro, Guanabara e norte do Paraná (GONÇALVES, 1945). Foi citada em Biritiba Mirim (AMANTE, 1960) e Salesópolis (MARICONI \& COL., 1963). Vejamos os dados das amostras coletadas e algumas informações anexas.

Aparecida: 26.VI.1964. Sauveiro em pastagem boa. Areias: 21.VI.1964. Pequeno ninho ao lado da estrada, em pastagem, muito próximo a um outro de $A$. bisphaerica e de outro de $A$. laevigata. Arujá: 14.III.1965. Grande sauveiro em pastagem paupérrima, em forte encosta. Idem, 5.XII.1965. Formigueiro em início de revoada. Bananal: 22.VI.1964. Grande colônia em encosta, em solo paupérrimo. Biritiba Mirim: 14.III.1965. Colônia à beira da estrada. Idem, 5.XII.1965. Pequeno sauveiro perto da estrada, em terra relativamente boa. Bras Cubas: 5.XII.1965. Ninho em terreno vasio, dentro do perímetro urbano. Caçapava: 26.VI.1964. Grande colônia em pastagem relativamente boa. Cachoeira Paulista: 21.VI.1964. Sauveiro localizado à margem da estrada. Campos do Jordão: 24.II.1965. Olheiros em barranco, no alto da serra. Alguns soldados fora, em carreiro, um dêles carregava material sêco. Idem, olheiro em outro barranco. Caraguatatuba: 19.VI.1964. Enorme sauveiro no alto da serra, de cêrca de $12 \mathrm{~m}$ de maior comprimento e $8 \mathrm{~m}$ de maior largura e com espêssa camada de terra sôlta. Formigas cortando e transportando fôlhas de "quaresmeira" (Tibouchina sp). Cruzeiro: 26.VI.1964. Grande formigueiro ao lado da estrada. Cunha: 20.VI.1964. Sauveiro em encosta íngreme, em pastagem pobre. Ferraz de Vasconcelos: 14.IIT.1965. Olheiros à margem da estrada, com formigas cortando e carregando capins vários. Guararema: 27.VI.1964. Colônia à margem da estrada, encostada em ninho vivo do cupim Cornitermes cùmulans (Kollar). Guaratinguetá: 21.VI.1964. Pequeno sauveiro ao lado da estrada, em terreno muito infestado. Guarujá: 1.VIII.1965. Sauveiro em barranco, no alto de um morro, nos limites da cidade. Formigas transportando grãos de milho inteiros. No interior de duas panelas foi encontrado material bem verde de "samambaia", "mimo-de-Vênus", "quaresmeira" e de "guanxuma rasteira" (respectivamente, Pteridium aquilinum (L.) Kuhn, Hibiscus rosa-sinensis L., Tibouchina sp. e Sida sp. Igaratá: 18.VI.1964. Sauveiro à beira da estrada. Ilhabela: 16.III.1965. Olheiros em barranco, há poucos metros do mar. Idem, sauveiro em canavial do Engenho D'Água. Itaquaquecetuba: 14.III.1965. Grande formigueiro em barranco da estrada. Idem, 4.XII.1965. Enorme sauveiro em terreno muito pobre, 
perto de colônia de A. bisphaerica. Jacareí: 18.VI.1964. Olheiros à beira da estrada, em pastagem muito pobre. Idem, sauveiro em terreno cultivado. Jambeiro: 26.VI.1964. Sauveiro em terreno inculto. Joanópolis: 23.II.1965. Grande sauveiro à beira da estrada. Idem, 4.XII.1965. Formigueiro em pastagem relativamente boa. Região pràticamente livre de saúvas. Lagoinha: 20.VI.1964. Sauveiro em terreno inculto, quase desprovido de vegetação. Idem, formigueiro localizado perto do anterior. Lavrinhas: 21.VI.1964. Grande sauveiro à beira da estrada. Formigas cortando e carregando "eucaliptos" (Eucalyptus sp.). Lorena: 21.VI.1964. Sauveiro perto da cidade, à beira da estrada. Idem, ninho perto do anterior, assemelhando-se um tanto a um de $A$. bisphaerica. Mogi das Cruzes: 14.III.1965. Pequeno sauveiro perto da estrada; ao ser revolvida a terra sôlta apareceram soldados do cupim Syntermes sp. Idem, 5.XII.1965. Sauveiro em encosta brava, em terreno muito pedregoso e pobre. Monteiro Lobato: 24.II.1965. Pequena colônia em pastagem. Natividade da Serra: 19.VI.1964. Sauveiro à beira da estrada, em pastagem, há cêrca de $30 \mathrm{~m}$ de uma colônia de $A$. bisphaerica. Idem, outro sauveiro nas proximidades das duas colônias anteriores. Nazaré Paulista: 23.II.1965. Grande sauveiro ao lado da estrada. Idem, 4.XII.1965. Sauveiro alto, perto da cidade. Idem, enorme colônia em terreno inculto. Paraibuna: 19.VI.1964. Grande formigueiro em pastagem. Idem, colônia ao lado da estrada. Pindamonhangaba: 26.VI.1964. Grande ninho à margem da estrada. Formigas cortando "eucaliptos" (Eucalyptis sp.). Piquete: 21.VI.1964. Sauveiro em encosta íngreme; possivelmente devido à forte declividade sua superfície dava idéia de ser ninho de $A$. bisphaerica. Idem, olheiros localizados em pastagem. Idem, 25.IV.1965. Sauveiro em encosta muito íngreme e pobre, nas proximidades da cidade e de colônias de A. bisphaerica e de A. laevigata. Piracaia: 29.VII.1965. Sauveiro em pastagem. Idem, 23.II.1965. Grande colônia à margem da estrada. Idem, 4.XII.1965. Pequeno formigueiro perto da cidade. Poá: 14.III.1965. Sauveiro em loteamento, muito semelhante a uma colonia de $A$. laevigata. Ao ser revolvido apareceram soldados do cupim Syntermes sp. Idem, ninho que assemelhava-se em parte com um de $A$. bisphaerica. Idem, 5.XII.1965. Pequeno formigueiro em campo, dentro do perímetro urbano, em terra muito ruim, próximo de colônia de A. bisphaerica. Queluz: 21.VI.1964. Olheiros ao lado da estrada e formigas em carreiro. Redenção da Serra: 19.VI.1964. Grande sauveiro em pastagem. Formigas cortando e transpor- 
tando fôlhas de "jacaré" (Piptadenia sp.). Idem; grande colônia ao lado da estrada. Roseira: 26.VI.1964. Enorme sauveiro à beira da estrada, em pastagem ótima. Salesópolis:.., 14. III.1965. Pequeno formigueiro em barranco. Santa Branca: 27.VI.1964. Sauveiro perto da estrada, quase encostado (há cêrca de $4 \mathrm{~m}$ de distância) em ninho enorme de $A$. bisphaerica. Santa Isabel: 18.VI.1964. Carreiro ao lado da estrada. Formigas com material vegetal. Idem, carreiro em pastagem, formigas transportando fôlhas de "figueira branca" (Ficus sp.). Santo Antônio do Pinhal: 24.II.1965. Pequeno formigueiro em pastagem boa, no alto da serra. Santos: 1.VIII.1965. Grande sauveiro à margem da estrada, em terra acumulada ao longo do asfalto. Os olheiros abriam-se ao longo do cordão de terra e não dos lados, pois o terreno, após o cordão, sofria inundações. Idem, 5.XII.1965, subdistrito de Bertioga, nas proximidades da cidade, em terra negra (região pràticamente livre de saúvaș), depredando "samambaia"(Pteridium aquilinum (L.) Kuhn). São Bento do Sapucaí: 25.II.1965. Pequeno ninho em barranco. São José do Barreiro: 22.VI.1964. Ninho à beira da estrada, em pastagem muito pobre, há poucos metros de uma colônia de $A$. bisphaerica. São José dos Campos: 27.VI.1964. Colônia ao lado da estrada. São Luís do Paraitinga: 20.VI.1964. Pequeno sauveiro ao lado da rodovia. São Sebastião: 15.III.1965. Sauveiro dentro da cidade, já atacado por formicida. Silveiras: 22.VI.1964. Pequeno sauveiro localizado em pastagem, próximo a ninhos de $A$. bisphaerica e de $A$. laevigata. Susano: 14.III.1965. Sauveiro em pastagem de "capim gordura" (Melinis minutiflora Beau), que estava sendo muito pouco atacado. Idem, 5.XII.1965. Grande colônia ao lado de eucaliptal, já atacada por formicida. Ao lado de canais, por onde saiam saúvas, havia outros por onde escapavam formigas carnívoras. Taubaté: 19.VI.1964. Grande sauveiro em pastagem de "capim gordura" (Melinis minutiflora Beau). Tremembé: 26.VI.1964. Enorme sauveiro, um dos maiores já vistos, localizado em eucaliptal. Ubatuba: 20.VI.1964. Sauveiro na baixada, ao lado da Estação Experimental do Instituto Agronômico, em terra arenosa (Bairro do Mato Dentro), há 6 $\mathrm{km}$ da cidade. Idem, sauveiro ao lado da estrada, já no alto da serra.

B) Atta bisphaerica Forel, 1908

Saúva de São Paulo, Goiás (Ilha do Bananal), Minas 
Gerais e Rio de Janeiro (BORGMEIER, 1939, 1959; GONÇALVES , 1960; ZAMITH \& COL., 1961).

A ocorrência da $A$. bisphaerica na região oriental do Estado de São Paulo foi verificada em Guaratinguetá (BORGMEIER, 1939), Lorena (GONÇALVES, 1960) e em Mogi das Cruzes e São José dos Campos (ZAMITH, MARICONI \& PAIVA CASTRO, 1961). Vejamos os dados das co letas efetuadas no período de junho de 1964 a dezembro de 1965.

Aparecida: 26.VI.1964. Sauveiro em pastagem muito boa e verde, apesar de capim estar sêco em quase todos os lugares. Areias: 21.VI.1964. Sauveiro situado nas proximldades de outro de $A$. sexdens rubropilosa e outro de $A$. laevigata. Arujá: 5.XII.1965. Pequeno formigueiro em capinzal. Bananal: 22.VI.1964. Grande sauveiro em cultura de "cana-de-açúcar" (Saccharum officinarum L.); formigas cortando essa planta. Biritiba Mirim: 5.XII.1965. Formigueiro em pastagem. Brás Cubas: 5.XII.1965. Enorme sauveiro, de cêrca de $12 \mathrm{~m}$ de maior comprimento, $8 \mathrm{~m}$ de maior largura e $0,8 \mathrm{~m}$ de maior altura, pronto para revoada; localizado dentro do perímetro urbano, em campo paupérrimo, quase sòmente com "barba de bode" e pequenas plantas semelhantes às dos cerrados. Seu aspecto era, em tudo, semelhante a um ninho de $A$. laevigata. Caçapava: 26.VI.1964. Ninho ao lado da estrada. Cachoeira Paulista: 21.VI.1964. Enorme sauveiro em pastagem verde. Cruzeiro: 21.VI.1964. Grande formigueiro em pastagem. Carreiro muito ativo, formigas sòmente com gramíneas. Cunha: 20.VI.1964. Grande formigueiro em pastagem relativamente boa. Idem, 24.IV.1965. Sauveiro inicial, apenas com um olheiro, em pastagem paupérrima; a rainha foi também coletada. Ferraz de Vasconcelos: 14.III.1965. Colônia à margem da estrada, perto da cidade. Ao ser revolvida a terra sôlta, apareceram dois tipos de soldados de cupim. Guararema: 27.VI.1964. Colônia em pastagem. Guaratinguetá: 21.VI.1964. Ninho em pastagem pobre, porém ainda com capim verde. Igaratá: 18.VI.1964. Formigueiro ao lado da estrada. Itaquaquecetuba: 4.XII.1965. Formigueiro perto da cidade, em terra paupérrima, perto de outras colônias da mesma espécie e de $A$. sexdens rubropilosa. Jacareí: 27.VI.1964. Grande colônia em pastagem. Jambeiro: 26.VI.1964. Ninho à margem da estrada. Lagoinha: 24.IV.1965. Grande sauveiro, de cêrca de $9,5 \mathrm{~m}$ de maior comprimento por $7 \mathrm{~m}$ de maior largura, em terreno inculto, em encosta muito íngreme. 
Lavrinhas: 21.VI.1964. Grande sauveiro em pastagem. Lorena: 21.VI.1964. Pequeno sauveiro em barranco. Mogi das Cruzes: 14.III.1965. Pequena colônia. Formigas conduzindo somente gramíneas. De um dos olheiros saiu um soldado do cupim Syntermes sp. Monteiro Lobato: 24.II.1965. Grande colônia em encosta muito íngreme, em pastagem. Natividade da Serra: 19.VI.1964. Sauveiro ao lado da estrada, em encosta, perto de duas colônias de $A$. sexdens rubropilosa. Paraibuna: 19.VI.1964. Grande sauveiro em pastagem. Formigas em intensa atividade de transporte de material. Idem, 15.III.1965. Enorme colônia, de cêrca de $12 \mathrm{~m}$ de maior comprimento e $11 \mathrm{~m}$ de maior largura, em encosta muito íngreme. Formigas cortando gramíneas. Pindamonhangaba: 26.VI.1964. Ninho ao lado da estrada. Alguns olheiros em atividade, apesar do frio e garoa. Piquete: 25.IV.1965. Grande sauveiro em pastagem, nas proximidades de outro de $A$. sexdens rubropilosa e outro de A. laevigata. Poá: 5.XII.1965. Sauveiro relativamente grande, em terra bem ruim, dentro do perímetro urbano, e próximo a outro de $A$. sexdens rubropilosa. Queluz: 21.VI.1964. Sauveiro em terreno inculto. Redenção da Serra: 19.VI.1964. Grande sauveiro em encosta de alto morro. Formigas em intensa atividade, apesar do frio; cortavam capins e duas espécies de plantas dicotiledôneas não identificadas. Roseira: 26.VI.1964. Formigueiro em ótima pastagem. Salesópolis: 14.III.1965. Enorme colônia, de cerca de $11 \mathrm{~m}$ de maior comprimento e $9,5 \mathrm{~m}$ de maior largura, em ótima pastagem bem limpa. Santa Branca: 27.VI.1964. Enorme colônia à beira da estrada, há distância de cêrca de $4 \mathrm{~m}$ apenas de uma outra de $A$. sexdens rubropilosa. Santa Isabel: 5.XII.1965. Pequeno sauveiro em encosta muito íngreme. São José do Barreiro: 22.VI.1964. Sauveiro há poucos metros de um de $A$. sexdens rubropilosa, em pastagem pobre. São José dos Campos: 27.VI.1964. Formigueiro em barranco. Idem, 26.IV.1965. Pequeno sauveiro em pastagem muito pobre e invadida por três espécies de cupim fazedores the monte que aflora à superfície da terra. São Luís do Paraitinga: 20.VI.1964. Sauveiro muito ativo, em encosta muito íngreme e solo bem pobre. Formigas em carreiros, de todos os lados. Idem, 24.IV.1965. Formigueiro de $6 \mathrm{~m}$ de maior comprimento e $5,5 \mathrm{~m}$ de maior largura, em pastagem bem pobre e encosta muito íngreme. Silveiras: 22.VI.1964. Sauveiro situado há apenas cêrca de $8 \mathrm{~m}$ de outro de $A$. laevigata e um pouco mais longe de um de $A$. sexdens rubropilosa. Susano: 5.XII.1965. Sauveiro ao lado da estrada. 
Taubaté: 19.VI.1964. Sauveiro ao lado da estrada. Tremembé: 26.VI.1964. Formigueiro em pastagem, formigas transportando "grama batatais" (Paspalum notatum Flügge), apesar do frio e garoa.

\section{C) Atta laevigata (F. Smith, 1858)}

Saúva de São Paulo, Território do Rio Branco, Amazonas, Pará, Maranhão, Ceará Pernambuco, Alagoas, Bahia, Rio de Janeiro, Minas Gerais, Goiás, Mato Grosso e Norte do Paraná, (LUEDERWALDT, 1926; BORGMEIER, 1939, 1959; GONÇALVES, 1945, 1960; PAIVA CASTRO \& COL., 1961).

Dos 52 municípios pesquisados, parece que o único já citado na bibliografia, como tendo esta saúva, é Santos (LUEDERWALDT, 1926), o que não pôde ser confirmado por nós.

Vejamos a relação dos municípios, dados das amostras coletadas e mais algumas informações.

Aparecida: 26. VI.1964. Olheiros em barranco. Formigas transportando "capim gordura" (Melinis minutiflora Beau) e "guanxuma" (Sida sp.). Areias: 21.VI.1964. Colônia situada nas proximidades de outra de $A$. sexdens rubropilosa e de outra de $A$. bisphaerica. Caçapava: 15.III.1965. Colônia de $6 \mathrm{~m}$ de maior comprimento e $4,5 \mathrm{~m}$ de maior largura, em pastagem muito pobre. Em intensa atividade, tanto na sede, como em carreiro, apesar do relativo frio. Transportando "capim gordura" (Melinis minutiflora Beau). Bem no centro da colônia havia um ninho vivo do cupim Cornitermes cumulans (Kollar), quase totalmente coberto pela terra sôlta do sauveiro. Cruzeiro: 21.VI.1964. Formigueiro em pastagem. Guaratinguetá: 21.VI.1964. Sauveiro perto da cidade. Carreiro com intenso movimento de formigas, que transportavam material de gramíneas e de dicotiledôneas. Lagoinha: 20.VI.1964. Sauveiro em pastagem de terra péssima, estando tôda a vegetação pequena completamente sêca. Carreiro de $120 \mathrm{~m}$ de comprimento, com intenso movịmento de formigas, com várias fileiras de insetos, que transportavam material de várias árvores, inclusive de "quaresmeira" (Tibouchina sp.). O olheiro de entrada do carreiro estava na própria sede do formigueiro. Lorena: 21.VI.1964. Grande sauveiro à margem da estrada. Piquete: 25.IV.1964. Pequeno formigueiro perto da cidade, em encosta muito íngreme, em pastagem paupérrima e nas proximidades de colonias de $A$. sexdens rubropilosa e de $A$. bisphaerica. São José do Barreiro: 
22.VI.1964. Grande colônia em pastagem paupérrima, quase sòmente com "barba de bode". São José dos Campos: 27.VI.1964. Grande sauveiro dentro do perímetro urbano (Vila Ema), de $9 \mathrm{~m}$ de maior comprimento e $7 \mathrm{~m}$ de maior largura. Carreiros de formigas ativos, passando pela sede da colônia, apesar de estar muito frio. Idem, 15.III.1965. Grande colônia em terra de fertilidade muito baixa, medindo $5,5 \mathrm{~m}$ por $4,5 \mathrm{~m}$ e sua altura, na região central, $0,9 \mathrm{~m}$. Silveiras: 22.VI.1964. Ninho bem ativo e não atacado, em pastagem. Formigas com material de gramíneas e de dicotiledôneas; vários soldados também transportavam material. $\mathrm{O}$ formigueiro estava bem perto de outro de A. bisphaerica $\mathrm{c}$ de outro de $A$. sexdens rubropilosa. Taubaté: 26.VI.1964. Sauveiro em terreno inculto, muito pobre. Apesar do frio e garoa, tôda a superfície da colônia estava coberta de formigas em atividade.

\section{5 - BIONOMIA}

A) Atta sexdens rubropilosa Forel, 1908

Pelo exame do capítulo anterior, vê-se que a "saúva limão" ou "saúva comum" ocorre nos 52 municípios (Fig. 2). Entretanto, há municípios que possuem áreas mais ou menos extensas, em que esta formiga ocorre com frequência mínima, sendo difícil encontrá-la; ao contrário, há outros muito infestados, se não tôda a área municipal, pelo menos grandes áreas.

Como exemplos de municípios que apresentam áreas em que a frequência desta saủva é baixa podemos citar: Biritiba Mirim, Campos do Jordão, Caraguatatuba, Ferraz de Vasconcelos, Guarujá, Joanópolis, Mogi das Cruzes, Monteiro Lobato (?), Nazaré Paulista (?), Poá, Santo Antônio do Pinhal, Santos, São Bento do Sapucaí, São Sebastião, Susano e Ubatuba. Deve-se a menor frequência da saúva, em certas áreas: 1) à maior divisão da terra; 2) ao cultivo mais intenso e progressista; 3 ) ao combate efetuado pelo agricultor; 4) ao fato das baixadas poderem sofrer inundação ou por motivo do lençol dágua estar muito próximo da superfície do solo; 5) por fatôres desconhecidos.

Assim, nos municípios do litoral (Caraguatatuba, Guarujá, Santos, São Sebastião e Ubatuba) torna-se, às vêzes, muito difícil encontrar saúvas, devido ao lençol dágua estar próximo à superfície do solo ou pelos terrenos serem inundá- 


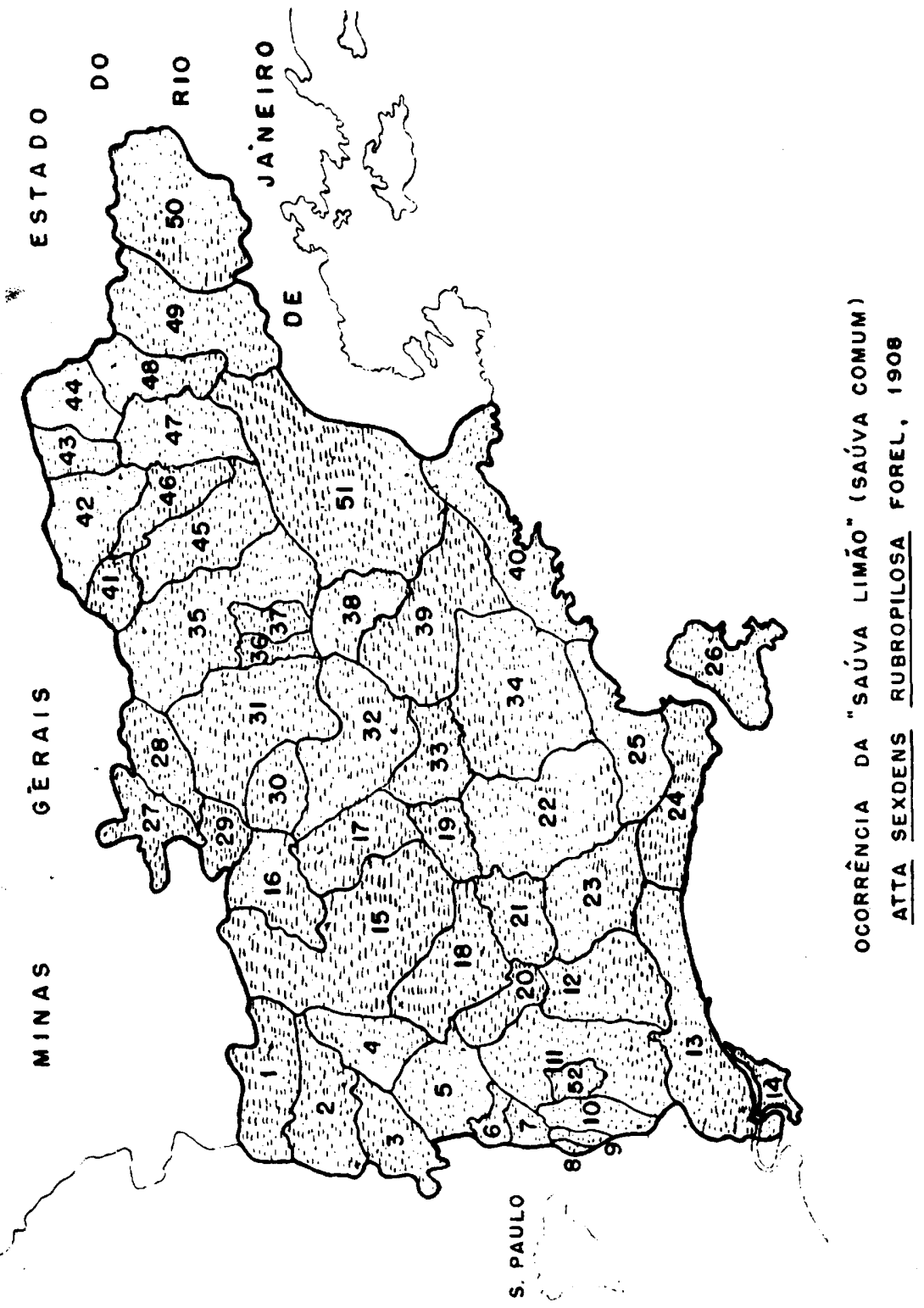

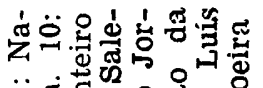
i่ . ठृّ

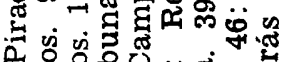
휴

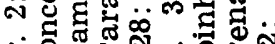

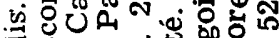

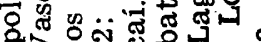
政

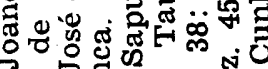
. N

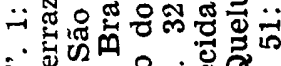
외

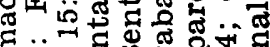
至 ๖

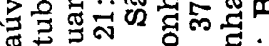

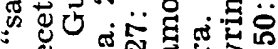

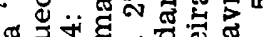

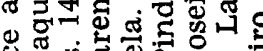

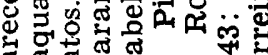

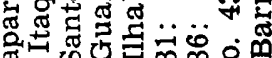
y

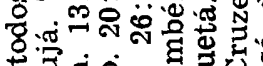

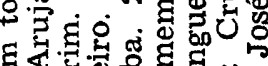

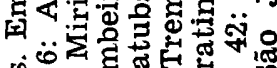

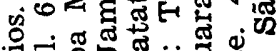

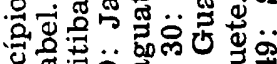

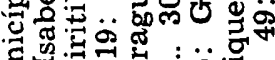

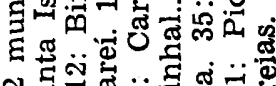
กิ

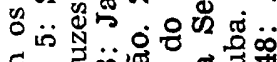
हू்

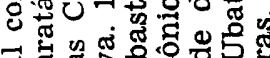
표웡

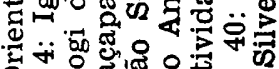

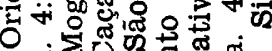

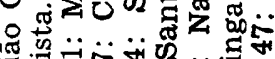

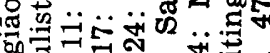
Ф น

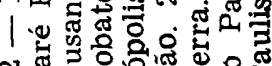

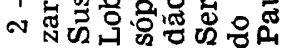
$\underset{\infty}{\infty}$ 
veis. Em Ilhabela, por motivo do terreno ser alto, as saúvas encontram "habitat" adequado.

Nesses municípios do litoral, nas áreas em que não há ou há pouca saúva, os danos às plantas são ocasionados pelas "quenquéns" (Acromyrmex spp.), que aparecem com frequência relativamente alta.

Os municípios de Caraguatatuba, Joanópolis, Mogi das Cruzes, Monteiro Lobato, Nazaré Paulista, Poá, Santo Antônio do Pinhal, São Sebastião, Susano e Ubatuba apresentam, infelizmente, também áreas com infestação mais intensa.

Municípios com grandes áreas de infestação forte a bem forte podemos citar: Areias, Bananal, Caçapava, Guaratinguetá, Ilhabela, Itaquaquecetuba, Jacareí, Jambeiro, Lagoinha, Natividade da Serra (?), Paraibuna, Pindamonhangaba, Redenção da Serra, Salesópolis, São José do Barreiro, São José dos Campos, Silveiras e Taubaté. O município que mais nos impressionou, tamanha era a infestação, foi o de Pindamonhangaba.

Com relação a vários municípios, nossas observações são menos completas, razão pela qual não foram êles incluidos nas duas relações acima.

Algumas plantas atacadas pela "saúva comum" já foram mencionadas no capítulo anterior; como regra geral, os danos não chegam a chamar a atenção, na maioria dos municípios, pois na região predomina a Pecuária. No Vale do Paraíba, onde a agricultura é intensa, as baixadas não permitem o estabelecimento das saúvas. Entretanto, em algumas regiões, principalmente naquelas mais próximas da Capital do Estado, onde também a agricultura é intensa (Ferraz de Vasconcelos, Itaquaquecetuba, Mogi das Cruzes, Poá, Susano, etc.), os danos fazem-se sentir bastante, às vêzes, não sòmente em árvores frutíferas, como em culturas anuais e florestais.

As colônias de $A$. sexdens rubropilosa podem estar localizadas perto, às vezes bem próximas, de outras de $A$. bis: phaerica (Itaquaquecetuba, Natividade da Serra, Poá, Santa Branca e São José do Barreiro); mais interessante é o fato das sedes das três espécies de saúva da região poderem também estar bem próximas entre si, como foi visto em Areias, Piquete e Silveiras.

Com frequência, nas pastagens e terrenos incultos da região, os sauveiros podem atingir grandes dimensões, como 
foi verificado em numerosos locais, inclusive Caraguatatuba e Tremembé.

Dentro do perímetro urbano foram observados formigueiros em Brás Cubas e Poá. Sauveiro encostado a ninho do cupim Cornitermes cumulans (Kollar) foi verificado em Guararema; nenhuma das duas colônias, pelo menos aparentemente, estava sofrendo a interferência do vizinho. Ao se revolver a terra sôlta de cima de colônias de Mogi das Cruzes e Poá apareceram cupins, principalmente de Syntermes sp.

Em Campos do Jordão, no alto de montanha, há mais de $1.200 \mathrm{~m}$ de altitude, foram encontrados olheiros em barranco, embora não fôsse possível encontrar a sede do sauveiro; interessante foi o fato de um soldado estar carregando material (fôlha sêca).

Um dos aspectos mais interessantes foi o sauveiro de Santos, localizado em terra sôlta colocada ao longo da estrada asfaltada; por motivo do terreno firme, dos lados, sofrer inundação, o sauveiro e os olheiros estavam localizados sòmente na terra colocada pelo homem.

Das três espécies de saúva, a $A$. sexdens rubropilosa foi a única difícil de se coletar nos dias relativamente frios a bem frios; mesmo após a retirada da. terra sôlta, ou ainda com o início da escavação de parte do sauveiro, geralmente era difícil aparecerem as formigas, quando não fazia calor.

Em Arujá, em 5.XII.1965, tivemos a oportunidade de presenciar a revoada de dois sauveiros. Possivelmente, devido à falta de chuvas, nesse município, Brás Cubas, Mogí das Cruzes e arredores, realizou-se esta revoada em época já um tanto tardia, após as chuvas do dia anterior. As operárias começaram a sair, para a superfície do ninho, às $14,50 \mathrm{~h}$; às $15,10 \mathrm{~h}$ já havia enorme quantidade de soldados e pouco depois os bitus e içás começaram a sair. Novamente pudemos comprovar que os dois sexos saem dos mesmos canais, embora seja crença quase geral dos agricultores, que os bitus saem de canais diferentes daqueles de onde escapam as içás. No outro sauveiro, já às $15,20 \mathrm{~h}$, a colônia se apresentava coberta de soldados e com as primeiras formas aladas. Os bitús e içás saiam dos canais e muitos subiam nos capins, arbustos e inclusive numa árvore que estava dentro do perímetro do formigueiro. Algumas içás subiram na árvore até cêrca de $2,5 \mathrm{~m}$ de altura. Após movimentarem as asas por tempo variável, as formas aladas levantavam vôo. Retirando-se uma das asas posterio- 
res das içás, pudemos ver que estas levantavam vôo; com a retirada das duas posteriores, as fêmeas voavam muito bem, mas hesitavam, por minutos, se levantavam vôo ou não. Com a retirada de uma parte da antena (flagelo), a içá encontrava mais dificuldade em iniciar a revoada, embora as quatro asas estivessem intactas; sem os flagelos das duas antenas, houve içá que não levantou vôo. Durante a revoada, o céu estava relativamente encoberto, mas o dia estava quente; uma chuva relativamente forte, que durou apenas cêrca de um minuto, não interrompeu a revoada.

\section{B) Atta bisphaerica Forel, 1908}

A "saúva mata pasto" foi constatada em 40 municípios da região (Fig. 3). Embora um dos dois nomes vulgares mais conhecidos da $A$. sexdens rubropilosa seja "saúva "omum", podemos afirmar que em vários municípios da região oriental foi mais fácil encontrar a $A$. bisphaerica .

Devido à frequência em que é encontrada na região oriental do Estado de São Paulo, pode-se levantar a hipótese de que a $A$. bisphaerica seja dá oriunda. Em apôio desta hipótese há ainda dois outros fatos: grande parte de São Paulo (provàvelmente mais da metade do Estado) não apresenta essa saúva e, nas demais regiões, onde ela ocorre (como em Piracicaba), a formiga é, de um modo geral, pouco frequente.

Os municípios em que a $A$. bisphaerica não pôde ser encontrada são 12: Campos do Jordão, Caraguatatuba, Guarujá, Ilhabela, Joanópolis, Nazaré Paulista, Piracaia, Santos, Santo Antônio do Pinhal, São Bento do Sapucaí, São Sebastião e Ubatuba. Em Joanópolis, Piracaia e Nazaré Paulista estiv€mos em duas ocasiões diferentes (fevereiro e dezembro de 1965), mas a $A$. bisphaerica não pôde ser encontrada.

Nas baixadas, quer do litoral, quer do Vale do Paraiba, a saúva não foi encontrada. Seus ninhos apareciam sòmente em terreno firme, quase sempre em pastagens.

As depredações ocasionadas às pastagens devem ser enormes, pois os sauveiros podem atingir proporções gigantescas. No capítulo anterior citamos algumas plantas cortadas, e um dos fatos mais interessantes, que veio contrariar o que se sabia, foi constatado em Redenção da Serra: as formigas cortavam, além de capins, duas espécies de dicotiledôneas rasteiras, que infelizmente, não puderam ser identificadas. 


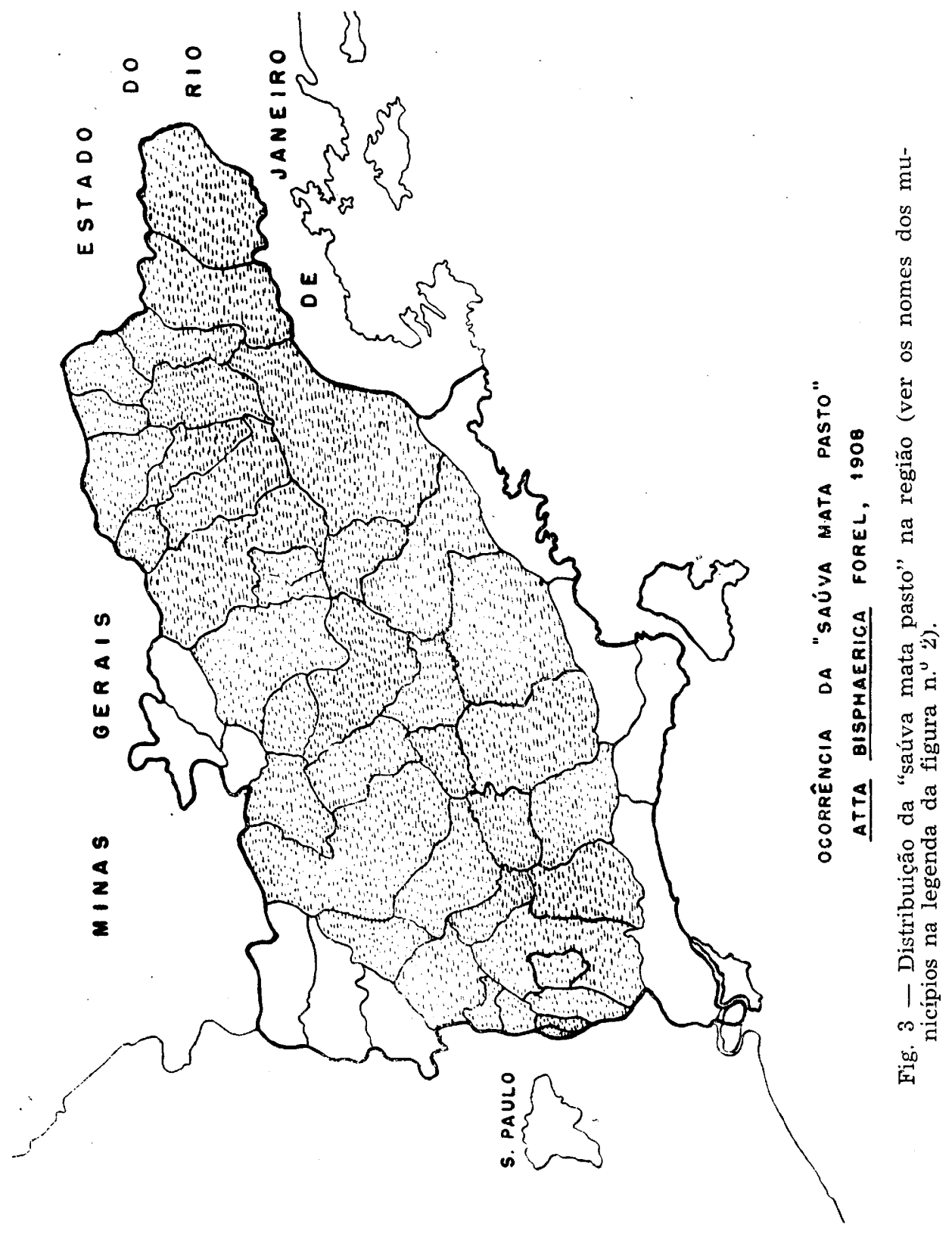


Como já foi dito para a espécie anterior, foram encontradas colônias de $A$. bisphaerica nas proximidades de outras de $A$. sexdens rubropilosa (Itaquaquecetuba, Natividade da Serra, Poá, Santa Branca e São José do Barreiro). Em três municípios (Areias, Piquete e Silveiras), foram vistos sauveiros, próximos uns dos outros, de três espécies (as duas já referidas e a $A$. laevigata), aparentemente vivendo muito bem.

$\mathrm{Na}$ região oriental, os sauveiros podem atingir enormes dimensões; as medidas de alguns dêsses formigueiros muito grandes, vistos em Brás Cubas, Lagoinha, Paraibuna, Salesópolis e Santa Branca foram citadas no capítulo anterior. O de Brás Cubas, com quase $100 \mathrm{~m}^{2}$ de área estava, por incrível que pareça dentro do perímetro urbano. Em Poá, também encontramos ninho dentro da cidade.

O revolvimento da terra sôlta, de cima de sauveiros de Ferraz de Vasconcelos e de Mogi das Cruzes, revelou também a presença de cupins.

Ao contrário do que sucedeu com a "saúva comum", as operárias de $A$. bisphaerica foram sempre encontradas cortando plantas ou transportando partículas de terra, para fora do sauveiro, ainda que a temperatura estivesse baixa.

Não tivemos a oportunidade de presenciar a revoada, embora o enorme sauveiro de Brás Cubas estivesse com os olheiros bem abertos, indício seguro dêsse aspecto biológico.

\section{C) Atta laevigata (F. Smith, 1858)}

Examinando-se o capítulo anterior, vê-se que esta saúva foi encontrada apenas em 12 municípios, marcados na figura n. 4: Aparecida, Areias, Caçapava, Cruzeiro, Guaratinguetá, Lagoinha, Lorena, Piquete, São José do Barreiro, São José dos Campos, Silveiras e Taubaté. Embora nossas observações sejam incompletas, parece ser saúva pouco frequente na região oriental: em Caçapava e São José dos Campos pudemos, entretanto, verificar que seus sauveiros são relativamente frequentes. Houve municípios que foram percorridos em duas ou três ocasiões sem que pudessemos verificar a presença desta saúva que, aliás, parece ser desconhecida de quase todos os lavradores da região.

Como foi dito para as duas espécies anteriores, essas formigas e a $A$. laevigata podem apresentar suas colônias muito perto entre si, aparentemente vivendo em harmonia (Areias, Piquete e Silveiras). 


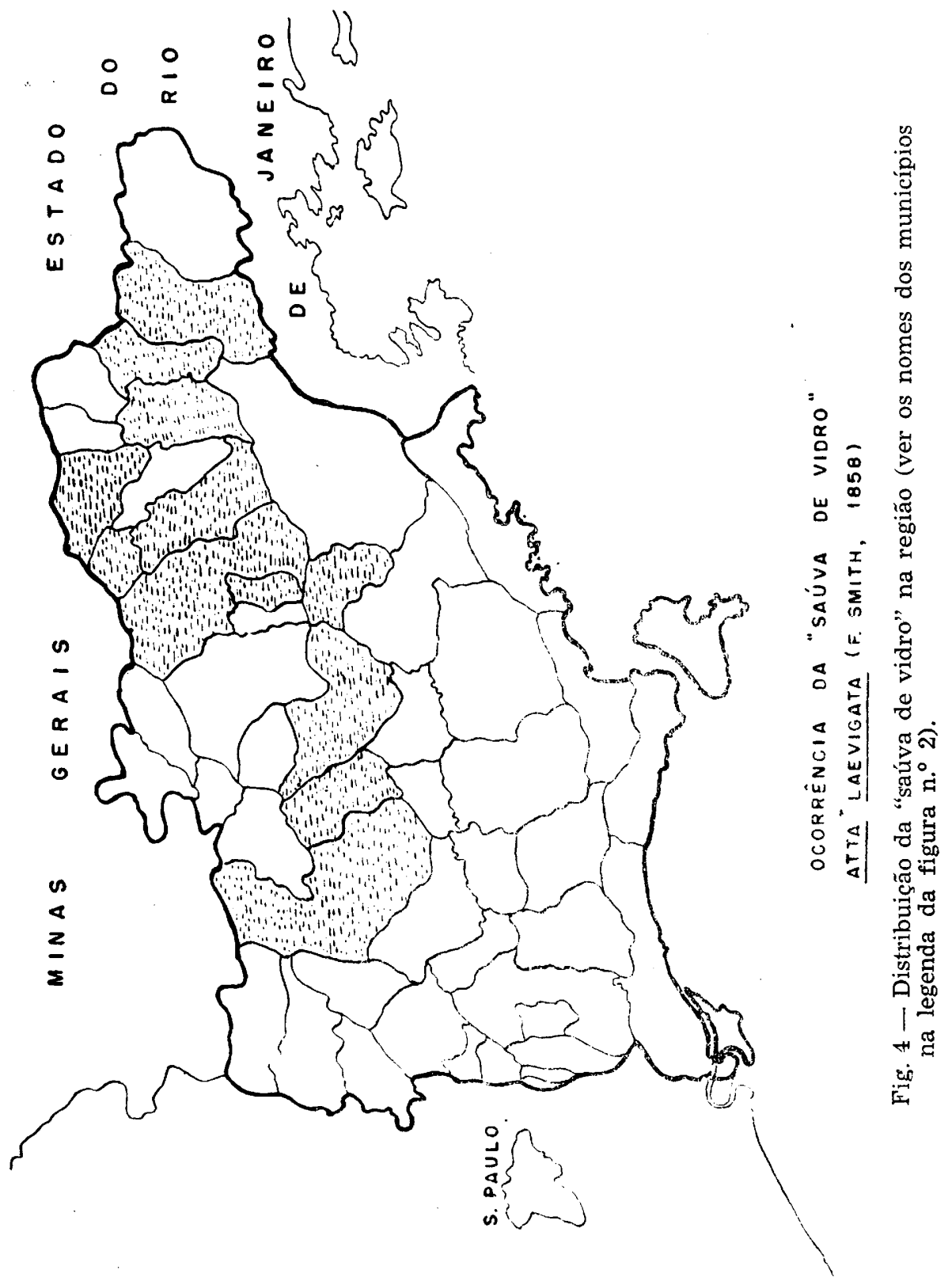


Os sauveiros da "saúva de vidro" podem atingir dimensões relativamente grandes, porém menores que as das duas outras espécies; entretanto, o maior sauveiro desta espécie já visto por nós (9 $\mathrm{m}$ por $7 \mathrm{~m}$ ), estava localizado dentro do perímetro urbano de São José dos Campos.

Em Silveiras, num carreiro havia soldados carregando matéria vegetal, embora a sede do formigueiro não demonstrasse estar em crise. Num mesmo carreiro foi comum encontrar-se formigas carregando gramíneas e dicotiledôneas (Aparecida, Guaratinguetá e Silveiras). O mais longo carreiro tinha cêrca de $120 \mathrm{~m}$ de comprimento (Lagoinha) e, a exemplo de outros casos, o olheiro de entrada do material encontrava-se localizado na própria sede do sauveiro.

Em Caçapava foi estudado um ninho que envolvia, por todos os lados, uma colônia do cupim de monte Cornitermes cumulans (Kollar); embora a terra do sauveiro encobrisse quase totalmente o monte do cupim, êste estava vivendo aparentemente em condições normais.

A semelhança do que foi verificado com a $A$. bisphaerica a $A$. laevigata corta material e transporta partículas de terra, para fora do sauveiro, ainda que a temperatura esteja baixa.

\section{6 - CONCLUSÕES}

A região oriental do Estado de São Paulo, constituída de 52 municípios, apresenta 3 espécies de saúva: Atta sexdens rubropilosa (saúva comum ou saúva limão), $A$. bisphaerica (saúva mata pasto) e $A$. laevigata (saúva de vidro). Aparecem em qualquer solo, desde que o terreno não seja inundável ou o lençol dágua não esteja perto da superfície.

A "saúva comum" foi encontrada em todos os municípios, mas com frequência extremamente variável; a "saúva mata pasto", que talvez seja oriunda desta região, foi constatada em 40 municípios, em alguns deles com maior frequência que a formiga anterior. A "saúva de vidro" foi achada em apenas 12 municípios e, exceto em dois deles, sua frcquência parece ser baixa a muito baixa.

As baixas temperaturas forçam a paralisação do trabatho externo da "saúva comum", mas não o das duas outras espécies.

Quase tôda a região necessita de orientação e conheci- 
mentos bionômicos e de combate às saúvas. Em alguns municípios, há necessidade premente de se proceder a um combate intensivo a essas formigas, tal é o flagelo. Em algumas das áreas onde se pretender desenvolver uma Pecuária mais progressista, urge combater principalmente a $A$. bisphaerica.

\section{7 - SUMMARY}

Fifty-two cities and their counties in the Eastern part of the State of São Paulo, Brazil, were, visited between July, 1964 and De-cember, 1965, in order to study "saúvas" (parasol ants).

This paper presents notes on "saúvas" that region: Atta sexdens rubropilosa Forel, 1908,A. bisphaerica Forel, 1908, and A. laevigata (F. Smith, 1858).

\section{8 - BIBLIOGRAFIA CITADA}

AMANTE, E., 1960 - Comentários sôbre a ecologia da saúva Atta sexdens rubropilosa Forel, 1908 nos meses frios. Divulg. Agron., Rio de Janeiro, 2: 34-35.

BOKGMEIER, T., 1939 - Nova contribuição para o conhecimento das formigas neotrópicas (Hym., Formicidae). Rev. Ent. 10 (2): 403428, 19 fig.

BORGMEIER, T., 1959 - Revision der Gattung Atra Fabricius (Hymenoptera, Formicidae). Studia Entom. 2 (n.s.): 321-390, 29 fig.

GONÇALVES, C.R., 1945 - Saúvas do sul e centro do Brasil. Bol. Firos. $2(3-4): 183-218,28$ fig.

GONÇALVES, C.R., 1960 - Distribuição, biologia e ecologia das saúvas. Divulg. Agron., Rio de Janeiro, 1: 2-10 ilust.

LUEDERWALDT, H., 1926 - Observações biológicas sôbre formigas brasileiklus, especialmente do Estado de São Paulo. Rev. Mus. Paul. 14: 185-304, 5 est.

MARICONI, F.A.M., A.P.L. ZAMITH, U. PAIVA CASTRO \& S. JOLY, 1963 - Nova contribuição para o conhecimento das saúvas de Piracicaba (Atta spp.) (Hiym. Formicidae). Rev. Agric., Piracicaba, 38 (2): 85-93, 1 fig.

PAIVA CASTRO, U., A.P.L. ZAMITH \& F.A.M. MARICONI, 1961 Contribuição para o conhecimento da "saúva de vidro" Atta laevigata (Fred. Smith, 1858). An. Esc. Sup. Agric. "L. Queiroz", Piracicaba, 18: 313-325, 2 est.

ZAMITH, A.P.L., F.A.M. MARICONI \& U. PAIVA CASTRO, $1961-$ Contribuição para o conhecimento da "saúva mata pasto" Atta bisphaerica Forel, 1908. An. Esc. Sup. Agric. “L. Queiroz”, Piracicaba, 18: 327-338, 2 est. 